\title{
Cultura política, mudanças econômicas e democracia inercial. Uma análise pós-eleições de 2014
}

\author{
Marcello Baquero \\ Rodrigo Stumpf González
}

\section{Introdução}

Os recentes debates sobre a qualidade da democracia no Brasil têm sido centrados em aspectos institucionais, particularmente processos eleitorais e necessidade de reformas no financiamento de campanhas. Alguma atenção foi dada para a existência de uma cultura política ambivalente em relação à democracia e à falta de confiança nas instituições representativas. Porém, a relação entre esses dois fatores e a economia tem sido pouco aprofundada. O objetivo deste artigo é o de propor outra perspectiva de análise da influência de fatores econômicos no desenvolvimento democrático.

Argumentamos que a bibliografia a respeito da relação entre economia e política apresenta perspectivas radicalmente diferentes, dando ênfase ora à economia, ora à política como variável independente. O que tentamos demonstrar, nesse caso, é que essas duas dimensões, em países como o Brasil, não podem ser vistas como mutuamente excludentes e precisam ser avaliadas compreensivamente para explicar a evolução do regime político.

Por exemplo, considerando os fatores econômicos das últimas duas décadas, que promoveram avanços sociais importantes no Brasil, esperar-se-ia que o fomento do crescimento econômico e a melhoria da renda de sua população se traduzissem em uma democracia estável que contasse com amplo apoio dos cidadãos e com graus altos de satisfação com o funcionamento das instituições. Igualmente, na eventualidade de o governo precisar tomar medidas consideradas impopulares, os cidadãos mostrariam paciência e dariam um voto de confiança ao governo incumbente. No entanto, esse não parece ser o caso do Brasil.

Tendo o Brasil institucionalizado uma democracia procedimental há mais de 25 anos, não é tão simples explicar os baixos níveis de apoio às instituições exemplificados pelo fato de que, em menos de um ano após a eleição de uma presidente que conquistou a maioria absoluta dos votos, tenham se iniciado movimentos pelo seu afastamento. Com base nessas observações, questionamos sobre o grau de influência da economia na deterioração das bases normativas e do apoio à democracia, levando ao que denominamos de democracia inercial. 
O objetivo central é o de introduzir, no debate sobre desenvolvimento democrático no Brasil, uma moldura conceitual que relaciona assimetrias entre economia e política, as quais desembocam em paralisia decisória e deslegitimação das instituições políticas e dos gestores públicos. Para alcançar esse objetivo, inicialmente, identificamos a necessidade de ir além de distinções simplistas entre economia e política, a fim de compreender com mais precisão as características da democracia brasileira contemporânea. Num segundo momento, identificamos e avaliamos os fatores que contribuem para plasmar uma democracia inercial. Utilizando os dados do Eseb ${ }^{1}$ numa perspectiva longitudinal, argumentamos que é possível detectar o momento em que se inicia uma caminhada em reverso democrático por parte dos cidadãos. Conclui-se que as assimetrias entre avanços democráticos meramente formais e investimentos sociais insuficientes produzem crises econômicas gerando uma cultura política cética e desconfiada, que compromete a consolidação da democracia num sentido maximalista.

O artigo está estruturado em cinco seções. Na primeira, "Democracia inercial", conceituamos esse tipo de democracia. Na segunda, "Assimetrias entre economia e política", examinamos as diferentes perspectivas teóricas a respeito da relação entre economia e política. Na terceira seção, "Cultura política no Brasil", examinamos o tipo de cultura no Brasil. A quarta seção, "Economia e cultura política no Brasil no século XXI", analisa os dados do Eseb empiricamente. A última seção, "Conclusões", por sua vez, consiste em uma discussão geral das implicações para o país e as pesquisas futuras, com base nos resultados aqui obtidos.

\section{Democracia inercial}

A institucionalização da inércia democrática se manifesta no desenvolvimento assimétrico de fatores que teorias, tanto no campo da ciência política como no da economia, argumentam que deveriam evoluir paralelamente. Para ilustrar como a inércia se materializa, recorre-se a um exemplo da física, que identifica a inércia como uma tendência do corpo em manter sua velocidade vetorial. Por exemplo, quando se está em um ônibus, o corpo de uma pessoa se desloca com a mesma velocidade do veículo. Cada vez que o ônibus faz um novo movimento, sua velocidade sofre uma alteração. Quando isso ocorre, é necessário se segurar para evitar uma queda, pois a tendência do corpo é manter a velocidade. A sensação é de que o corpo está se opondo à mudança de velocidade. Entretanto, quando o ônibus viaja em linha reta a uma velocidade constante, não é preciso fazer esforço para ficar parado dentro dele (ambos evoluem paralelamente).

\footnotetext{
${ }^{1}$ O Eseb (Estudo Eleitoral Brasileiro) é uma pesquisa pós-eleitoral de natureza acadêmica, associada ao Projeto Comparative Study of Electoral Systems, da University of Michigan, coordenado por Rachel Meneguello (Cesop/Unicamp).
} 
O princípio subjacente da inércia ocorre, portanto, quando um elemento se move em uma direção e outro elemento, que deveria também se movimentar na mesma direção, resiste, com a força do movimento na direção oposta.

O conceito de inércia foi incorporado, no âmbito da economia, por Mario Henrique Simonsen, ex-ministro da Economia, para caracterizar a inflação brasileira, que denominou de "inflação inercial". Tal adjetivo foi utilizado para se referir à ideia de memória inflacionária que se instala no imaginário coletivo, em que o índice atual de inflação envolve a inflação presente mais a expectativa futura. Para Simonsen, a inflação se mantém no mesmo patamar sem aceleração inflacionária e é decorrente de mecanismos de indexação que podem ser formais e informais. Formais, com regras específicas e legais de aumento, a exemplo de aluguéis e mensalidades escolares. Informais, quando os agentes são seguidores de preço, ou seja, aumentam o preço porque os outros também o fizeram.

Em épocas de inflação elevada (nos anos de 1970 e 1980), contratos de diversos tipos tinham cláusulas de correção que eram autoaplicáveis. Isso gerou, na população, um comportamento inflacionário: transferia-se para o mês seguinte a taxa de inflação do mês passado mesmo que não houvesse pressões de demanda ou de custo. No caso brasileiro, por exemplo, por ter sido real a correção da inflação no período 1964-1984, ou seja, sem inércia, ocorreu o que foi denominado pelos acadêmicos de economia na época de "milagre econômico", com crescimentos reais significantes e positivos.

Desse modo, a materialização de comportamentos inconsistentes entre o estado da economia e o comportamento das pessoas ocorre quando estes caminham em direções opostas, possibilitando o surgimento da inflação inercial, uma vez que os preços praticados oferecem resistência às políticas de estabilização para atacar as causas primárias da inflação. É a chamada memória inflacionária. Essa inflação inercial é decorrente de mecanismos de indexação, que reajustam o valor das parcelas de contratos pela inflação do período passado, ou seja, mesmo que não haja uma razão para o preço aumentar, ele aumenta baseado nessa memória inflacionária. Para Bresser-Pereira:

A inércia inflacionária se caracterizava por um permanente conflito distributivo em função das defasagens nos ajustes de preços realizados pelos agentes que, dessa forma, estavam permanentemente equilibrando e desequilibrando os preços relativos (Bresser-Pereira, 2007, p. 24).

Para o autor, a ideia de que expectativas e credibilidade são tomadas como dados tem gerado grandes equívocos em termos de política macroeconômica, pois as expectativas dos agentes econômicos não são tão racionais a ponto de corresponderem ao modelo ideal. Há, segundo o autor, um componente faltante nessa equação e que se refere à confiança recíproca entre os atores sociais. A ausência dessa confiança produz assimetrias entre o que é desejado e o que acontece na realidade. 
Aplicando esse conceito para o processo de construção da democracia, que envolve várias dimensões (econômica, política, social e cultural), e tomando como base os pressupostos da teoria da escolha racional e institucional, passou-se a aceitar, sem maiores questionamentos, a ideia de que, em virtude da racionalidade subjacente dos atores sociais num sistema político, os avanços formais e institucionais acarretariam automaticamente a solução de problemas socioeconômicos e políticos. Não haveria, assim, grandes preocupações com o processo de politização ou estruturação de uma cultura política, na medida em que os procedimentos institucionais seriam suficientes para catalisar uma cultura política democrática.

Entretanto, essa perspectiva não tem se comprovado, pois, quando crises econômicas se instauram, elas produzem crises de credibilidade e legitimidade do governo incumbente, levando os cidadãos a se posicionar contra as medidas ou reajustes econômicos recomendados para solucionar problemas imediatos de caráter material, colocando em xeque a credibilidade e, em última análise, a própria legitimidade de um governo democraticamente eleito.

Tal situação, para Rosanvallon (2008), não coloca a democracia em perigo de desaparecer, pois esse sistema tem capacidade de mudar e se adaptar, evitando seu declínio. Essas mudanças vão além da dimensão eleitoral, a qual é considerada uma forma tradicional de representação, que tem declinado em termos de importância. Desse modo, a hipótese de Rosanvallon é de que a "inabilidade da política eleitoral/representativa em manter as suas promessas tem levado ao desenvolvimento de formas indiretas de democracia" (p. 274). Em princípio, concordamos parcialmente com essa afirmação; entretanto, o que está evidenciado é a manutenção de uma democracia frágil a despeito de formas alternativas de engajamento político que têm aparecido na última década.

No caso brasileiro, no contexto atual, pode não redundar numa regressão autoritária ou colapso institucional (ainda que o processo de afastamento da presidente Dilma possa ser interpretado por alguns dessa forma), pois existem mecanismos institucionais que potencialmente impediriam tais ocorrências, mas o dano maior se dá na instabilidade política permanente, fruto da assimetria entre o que o governo propõe, o que a sociedade acredita ser necessário e o que ela está disposta a aceitar em termos de sacrifício.

Nessas circunstâncias, produz-se uma assimetria que gera inércia entre o desenvolvimento de procedimentos democráticos formais, concomitante com uma memória, catalisada pelos próprios gestores públicos e assimilada pela população, de manter uma ação política com base em práticas tradicionais e ultrapassadas. Tal assimetria prejudica o desenvolvimento de uma sociedade em virtude de produzir efeitos contraditórios aos esperados pela democracia representativa, ou seja, materializa efeitos de imobilidade ou resistência às mudanças propostas pelos órgãos públicos, uma vez que não há reação 
quando estão em contato um com o outro - procedimentos formais e cultura política. A democracia inercial, em oposição a outros tipos de democracia (deliberativa ou representativa, por exemplo), gera, assim, um movimento de reprodução de práticas políticas de tal forma que padrões de comportamento negativo do passado se (re)atualizam no presente. Ou seja, a memória do passado age como fator estruturante na constituição de um tipo de cultura política que apresenta uma crescente incongruência entre valores normativos da democracia e avaliação das instituições políticas (Baquero e Morais, 2015).

Nessa perspectiva, uma democracia inercial apresenta as seguintes características:

1. Em virtude de condições externas favoráveis, em determinados períodos, aumenta o grau de competitividade de um país no mercado internacional em face do crescimento econômico moderado e aumento da capacidade de arrecadação de impostos.

2. Uma vez estabelecidos padrões de desigualdade e despolitização dos cidadãos, materializam-se atitudes e comportamentos que resistem a mudanças impostas pelo contexto hegemônico da política.

3. Produz uma perda progressiva de valores democráticos.

4. Ativa uma "memória simbólica" de um passado melhor.

5. Propicia o reaparecimento de práticas políticas que erodem princípios democráticos.

6. Gera o surgimento de uma cultura política híbrida.

7. Institucionaliza relações terciárias (Estado-cidadão) em vez de relações secundárias (partidos políticos).

8. Produz instituições deficientes e descontextualizadas que privilegiam a desigualdade econômica e política, desembocando numa inércia democrática.

A democracia inercial, portanto, se refere a uma situação na qual os vícios de um passado autoritário, que afetavam negativamente os princípios democráticos, não são eliminados no novo contexto de democratização, com consequências deletérias para o desenvolvimento econômico e político e para a construção de uma cultura política participativa. Exemplos desses vícios são: clientelismo, paternalismo, privatismo, corrupção e patrimonialismo. Tais elementos produzem um efeito contaminado na democracia contemporânea. Assim, é possível ter estabilidade governamental com a ausência de estabilidade democrática. As conquistas formais da democracia, nesse contexto, não eliminam práticas políticas negativas corrosivas, e a desigualdade social e econômica é reproduzida em novos cenários tecnológicos (por exemplo, o analfabetismo tradicional é substituído por analfabetismo digital). 
Desse modo, a relação entre democracia e qualidade de vida é bidirecional, isto é, a democracia precisa responder às demandas dos cidadãos, porque, dependendo do grau de respostas sociais, o apoio à democracia e suas instituições pode aumentar ou diminuir. Quando um padrão de demandas não atendido se materializa, também se constitui uma cultura política de desconfiança. Por esse motivo, a menos que medidas sejam projetadas para corrigir essa situação, as irregularidades vão continuar a manifestar aquilo ao que O'Campo e Malagõn (2009) se referiram como a "tragédia liberal", que é a contradição histórica entre liberalismo econômico e liberalismo político. Vamos mais longe e argumentamos que o que se institucionaliza é uma "democracia inercial". Nesse tipo de democracia, as demandas da sociedade ganham força, enquanto o modelo de desenvolvimento econômico reduz a capacidade estatal de responder a essas reivindicações.

Pensamos que a prevalência histórica de assimetrias entre economia e política no Brasil contribui para o atraso democrático numa dimensão social e emancipatória. Para respaldar essa afirmação, buscamos evidências na bibliografia histórica.

\section{Assimetrias entre economia e política}

Estudos sobre a relação entre economia e política é um tema tão antigo quanto a Política, de Aristóteles, e A democracia na América, de Tocqueville. Em um contexto contemporâneo, Lipset (1959) defendeu como fundamental uma base de desenvolvimento econômico para a existência de uma democracia. Moore (1967), em seu estudo do surgimento das democracias modernas, aponta fatores econômicos como intervenientes no seu sucesso.

Na esteira do trabalho de Lipset, travou-se um debate sobre a influência ou não de fatores econômicos como pressuposto da democracia, com a contribuição de diversos autores como Helliwell (1994), Barro (1999), Przeworski et al. (2000) e Przeworski, Cheibub e Limongi (2003).

A perspectiva de uma terceira onda da democracia (Huntington, 1994) se baseia na expansão do número de países enquadrados como democráticos, em geral a partir de uma concepção institucional e minimalista de democracia. Alguns trabalhos mais recentes passaram a considerar as condições não para o surgimento da democracia, mas para sua estabilidade e qualidade.

Porém, quando um país se encontra no umbral de uma crise econômica, independentemente do tipo de regime que possua, produz-se uma "destruição criativa" (González, 2012). Esse tipo de destruição, principalmente em países que ainda não consolidaram a dimensão material da democracia, afeta as camadas médias e pobres da população, pois são elas que são chamadas a pagar os custos de governos incapazes de 
desenhar e implementar modelos econômicos com sólidos fundamentos, via corte de recursos em áreas sociais estratégicas e aumento de impostos. Tal situação, em nossa opinião, mostra contundentemente a existência de uma relação entre a ocorrência de crises econômicas e a deterioração da democracia, o que tem ocorrido frequentemente durante o século XX e início do XXI, em economias emergentes como o Brasil.

A esse respeito, Fuchs e Klingemann (1995) sugerem que as democracias da terceira onda enfrentam obstáculos políticos e econômicos que podem afetar negativamente o apoio ao regime e enfatizam que a legitimidade das democracias depende, cada vez mais, do desempenho econômico.

Numa outra direção, argumenta-se que a legitimidade da democracia depende de fatores políticos culturais. Além dos fatores econômicos, a corrente teórica da cultura política, seguindo a tradição do trabalho de Almond e Verba (1989), propõe que se considerem os fatores culturais na avaliação da estabilidade dos regimes políticos. Inglehart e Welzel (2009) propõem que as transformações da cultura política são impactadas pelas mudanças econômicas, com a segurança material servindo de base para o desenvolvimento da autonomia individual e um melhor funcionamento da democracia, uma vez que produziria uma cidadania assertiva.

Por sua vez, estudos de natureza sociológica argumentam que a desigualdade econômica vem acompanhada de uma escassa mobilidade social, reduzindo a institucionalização de comportamentos éticos e morais. A instabilidade social e política, que resulta da relação assimétrica entre economia e política, afeta o desenvolvimento de uma cultura política participativa e democrática.

Quando a ética e a moral são jogadas para uma dimensão secundária, os responsáveis pela condução da política atribuem à sociedade civil papel insignificante. Desse modo, o papel dos atores políticos no processo de construção democrática também é essencial. A esse respeito, Perez-Liñán e Mainwaring (2014) argumentam que a probabilidade de sobrevivência das democracias é maior quando os atores políticos demonstram uma forte preferência normativa pela democracia e adotam uma postura de moderação política. Tais preferências, segundo os autores, não são determinadas historicamente; porém, geralmente tendem a se mostrar estáveis. Isso implica que, para a sobrevivência de um regime democrático, é fundamental que os cidadãos o percebam como sendo legítimo. Para alcançar esse objetivo, é imperativo que exista um desenvolvimento econômico contínuo e uma classe média predominante.

Nesse sentido, a estabilidade macroeconômica e a promoção do bem-estar da população não se definem unicamente por preços relativamente estáveis e um ajuste fiscal definido por superávits primários, mas por pleno emprego, inflação sob controle, taxa média de juros moderada, taxa de câmbio competitiva e pelo caráter sólido das contas do Estado e do Estado-nação. Igualmente importante é a base normativa de apoio às políticas 
econômicas e sociais, mesmo que, em alguns casos, sejam impopulares, manifestada pela confiança dos cidadãos no governo, pois acreditam nos esforços deste e na eficiência das instituições responsáveis pelos ajustes econômicos. Não tem sido esse o caso do Brasil nos últimos anos.

Os déficits fiscais e a fragilidade das instituições fiscais têm se constituído, portanto, em uma das principais causas da volatilidade macroeconômica e do baixo crescimento relativo do país. Essa volatilidade explica também a manutenção de índices significativos de desigualdade social e de oportunidades iniciais e a concentração de renda.

Ao analisar a evolução da democracia no Brasil, constata-se que, a despeito dos avanços sociais promovidos nos últimos anos, a desigualdade continua a predominar, combinada com um modelo econômico que privilegia o mercado na regulação das relações sociais, criando bases para o fortalecimento da polarização social. Isso ocorre porque, apesar de o desenho das políticas públicas se orientar para as classes populares, quando uma crise econômica emerge, são essas classes as primeiras a pagar o custo e a percepção é de que houve abandono delas pelo Estado, diminuindo, consequente e deliberadamente, sua capacidade organizativa.

O conjunto de conceitos que buscam explicar como a economia afeta ou não o fortalecimento democrático é vasto, porém insuficiente. Dependendo de como se estrutura o argumento, em alguns casos, a economia influencia a democracia e, em outros, a relação é inversa. O que fica evidente, entretanto, é o reconhecimento da existência dessa associação. Assim, a questão de fundo é encontrar explicações plausíveis para o fato de países em desenvolvimento, que detêm procedimentos democráticos formais, não conseguirem institucionalizar valores republicanos e uma cultura política sólida.

Uma das principais explicações para esse paradoxo provém de Lipset no seu já clássico estudo Some social requisites of democracy: economic development and political development, publicado em 1959. Lipset mostrou a consistência do vínculo teórico entre nível de desenvolvimento de um país e probabilidade de ser democrático. A premissa de sua teorização era de que, "quanto melhor a condição econômica de um país, maiores as probabilidades de que sustente uma democracia" (Lipset, 1959, p. 75). Tal formulação se transformou num teorema quase universal, pois, para Lipset, a relação entre desenvolvimento econômico e democracia é empiricamente verificável.

No âmago dessa discussão, assume centralidade o conceito de igualdade, no sentido tanto político quanto econômico. Mudanças de natureza democrática se materializariam em função das condições econômicas, as quais promoveriam uma cultura democrática, com base na tolerância e na rejeição a formas autoritárias de governo. PerezLiñán e Mainwaring (2014), no início do século XXI, dão respaldo às conclusões de Lipset, na década de 1960, que apontavam para o efeito positivo da modernização na receptividade de normas e valores que amenizam o conflito, penalizam posições políticas 
MARCELLO BAQUERO; RODRIGO STUMPF GONZÁLEZ

extremas e recompensam instituições políticas com orientação democrática. Contrariamente, uma sociedade dividida entre uma massa empobrecida e uma pequena elite resultaria ou numa oligarquia ou numa tirania.

Nessa perspectiva, o desenvolvimento econômico (urbanização, riqueza, saúde e educação) se constituiria numa dimensão fundamental para o fortalecimento democrático na dimensão substantiva. É por isso que Lipset, ao considerar o processo de democratização não unidirecional, optou por denominá-lo como requisito e não prérequisito da democracia. Essa diferença é central, em nossa opinião, para entender o processo de construção democrática como uma caminhada compreensiva e não resultado de uma única variável; ou seja, em países como o Brasil, o desenvolvimento socioeconômico não é condição suficiente para o enraizamento de um sistema democrático. É necessário levar em conta, simultaneamente, outros fatores. Assim, os atributos de uma democracia efetiva se entrelaçam num sentido holístico e não necessariamente causal, pois, dependendo da conjuntura de cada país, ora as instituições são essenciais, ora aspectos relacionados com a cultura política o são, e, frequentemente, as duas dimensões são centrais.

Ao negligenciar a simultaneidade dessas dimensões conceituais, engessou-se dicotomicamente a classificação de sistemas políticos tanto no sentido econômico (desenvolvido e não desenvolvido) quanto na dimensão democrática (democrático e autoritário), limitando a compreensão do vínculo entre desenvolvimento econômico e democracia. Alguns exemplos desse engessamento estão materializados nos estudos de Rostow (1960), que argumenta existir uma relação unilinear entre desenvolvimento econômico e democracia.

Da mesma forma, no final da década de 1960, Samuel Huntington (1968) dicotomizou desenvolvimento econômico e desenvolvimento político na sua análise dos fatores que promovem a ordem política. $O$ argumento central do autor, que influenciou o pensamento político-econômico dos países em desenvolvimento, era de que, quando o nível de mobilização dos cidadãos excede a capacidade do Estado em responder às demandas, se não houver uma institucionalização das instituições de mediação política, a democracia poderá estar ameaçada. A relação estabelecida era que, quando o desenvolvimento econômico aumenta, a mobilização política cresce numa proporção mais rápida do que o desenvolvimento das instituições, abrindo o caminho para a instabilidade política. Tal posicionamento foi modificado em estudo posterior, $A$ terceira onda, no qual Huntington (1994) reconheceu que a modernização se constitui em fator essencial do processo de democratização.

Nos anos de 1990, Rueschemeyer, Stephens e Stephens (1992), numa perspectiva histórica, identificaram a classe proprietária como o principal obstáculo para a democratização, comparado com os efeitos benéficos de uma classe trabalhadora 
organizada. Nesse sentido, destacam a importância da urbanização como fator desencadeador de fortalecimento da classe trabalhadora e do enfraquecimento da elite na construção de uma sociedade democrática. Embora a relação teórica seja consistente, do ponto de vista metodológico, há dificuldades na conceituação de desenvolvimento e democracia.

Para tentar sanar problemas de natureza sociométrica, vários estudos de natureza empírica foram realizados para testar a relação entre desenvolvimento econômico e democracia. Quiçá o principal estudo seja o de Przeworski et al. (2000), cujo objetivo era determinar se o desenvolvimento produz democracia ou se se resume a sua sustentação, uma vez estabelecida. A pesquisa por eles conduzida, de natureza longitudinal comparativa, de 1950 a 1990, em 135 países, foi desenvolvida com base na postulação de dois modelos - exógeno e endógeno. O modelo exógeno propõe que países com elevados índices de Produto Interno Bruto (PIB) são menos propensos a ter regressões autoritárias, pois, quando um país alcança um nível elevado de riqueza, medido em termos do PIB per capita, a probabilidade de retornar a um regime autoritário é quase zero; já o modelo endógeno considera que, quando um país atravessa um determinado umbral de desenvolvimento, a transição para a democracia se torna inevitável. Para Przeworski e seus colaboradores, o modelo exógeno é empiricamente verificável, enquanto o modelo endógeno não se confirma.

Pesquisas posteriores para avaliar a associação entre desenvolvimento e democracia foram desenvolvidas por Boix e Stokes (2003), que ampliaram o período examinado por Przeworski e associados, de 1850 a 1950. Nesse estudo, questionam os resultados da equipe de Przeworski, sem, no entanto, demonstrar a validade dos seus próprios indicadores. Apesar disso, chegam à conclusão de que, uma vez alcançado um determinado nível de desigualdade, as massas automaticamente passam a demandar mudanças, via políticas distributivas, por uma melhor democracia. Essa formulação, entretanto, quando aplicada ao contexto brasileiro, carece de evidência.

Houle (2009), por sua vez, demonstrou que, enquanto a desigualdade não tem impacto na democratização, níveis elevados de desigualdade reduzem a probabilidade de a democracia se consolidar. Altimir (1994) corrobora essa observação ao constatar que o impacto da desigualdade econômica no processo de construção democrática deriva de modelos de desenvolvimento econômico que produziram exclusão social sem conseguir reduzi-la a patamares eticamente aceitáveis, conspirando, dessa forma, contra o princípio de inclusão social. Uma vez que esses modelos eram de origem exógena, não conseguiam explicar por que, a despeito da consolidação formal da democracia, as condições de vida da população se mantinham precárias. Assim, o fenômeno perverso da construção democrática criou uma situação em que a desigualdade aumenta a pobreza que, por sua 
vez, expande as desigualdades e na qual o crescimento econômico e o crescimento da pobreza se tornam compatíveis.

Como pode ser visto, apesar das variadas formas de examinar a relação entre economia e democracia, há uma convergência com o argumento original de Lipset a respeito do papel do crescimento econômico considerado quase determinante para a sobrevivência das democracias. Não há, entretanto, uma explicação teórica sólida sobre por que é assim. Neste artigo, propomos que a assimetria entre o nível crescimento econômico e o dos investimentos sociais coloca em risco a estabilidade econômica e política, uma vez que não gera uma cultura política empoderada mas sim híbrida e, num ponto extremo, inercial.

Nessa fase da história, pensamos que não se pode ignorar ou subestimar a influência que a desigualdade social tem na construção de uma cultura política ativa e participante no presente. Ao mesmo tempo, parece-nos irrefutável a constatação de que os diferentes modelos de políticas de desenvolvimento, ao longo da história do Brasil, tiveram uma influência limitada na resolução de desigualdade social, indicando que os fatores de sua reprodução estão concentrados no poder político. Tal situação fica clara no estudo de Burchardt que citamos a seguir:

A perpetuação da desigualdade social, a despeito de governos democráticos
consolidados, continua a ter implicações importantes para a teoria democrática,
porque mostra a necessidade de ligar novamente a questão da participação
política com desigualdade social (Burchardt, 2012, p. 26).

Não nos surpreende, portanto, constatar que, quando crises econômicas se instalam num país onde existe uma precariedade econômica estrutural, afetando as camadas mais vulneráveis, esses grupos manifestam seu descontentamento com o sentimento de que foram abandonados pelo Estado, apoiando líderes (neo)populistas, institucionalizando um tipo peculiar de democracia - uma democracia incompleta. Nesse cenário, alguns autores (Vilas, 1997, p. 24) caracterizam as democracias emergentes como um conjunto de Estados próximo da dimensão hobbesiana, em virtude da precariedade social da maioria da população e da ausência de uma sociedade organizada. Nessa perspectiva, o Estado é absoluto em relação à sociedade, uma vez que detém todo o poder de impor a ordem e a organização da sociedade, pois as relações entre o Estado e as classes populares se processam principalmente via aparato coercitivo do Estado.

A monopolização do poder do Estado por gestores sem criatividade, que emulam modelos econômicos externos e os aplicam descontextualizadamente no nosso país, contribuiu para que a manutenção da desigualdade afete a legitimidade dos governos, especialmente quando analisada em termos de salários e acesso aos bens públicos, tais como saúde e educação. A presença desses fatores sinaliza para a existência de uma 
correlação entre crescimento econômico e desigualdade social, nem sempre evidente em análises probabilísticas.

Do ponto de vista de causalidade, tal correlação é complexa, pois depende do tempo, do espaço, da conjuntura e do contexto dos países analisados. O que é verdade em um período pode não se aplicar a outro. Porém, quando o padrão de democratização ao longo do tempo não consegue estabelecer bases equitativas de atendimento social em virtude de deficiências estruturais de caráter econômico e político, torna-se imperativo (re)avaliar as diferentes teorias, com base nas características do país sob análise.

Por exemplo, a constatação de que o aumento dos níveis de renda atenua os efeitos da pobreza e que o crescimento econômico pode ser mais ou menos efetivo em alcançar esse objetivo é bem conhecida e tem recebido atenção significativa na busca de um crescimento que favoreça os pobres. O que não tem recebido uma atenção mais adequada é a direção inversa, ou seja, que a pobreza pode, de fato, ser parte da razão para explicar o desempenho deficiente em termos de crescimento, criando um círculo vicioso, em que resultados baixos do crescimento resultam em elevados índices de pobreza, os quais, por sua vez, resultam em baixo crescimento.

Essa percepção sinaliza que a naturalização de práticas políticas e econômicas deletérias se pereniza porque o Estado é "capturado" por elites predatórias, pelas imperfeições do mercado de capitais, pela desigualdade de oportunidades (principalmente em termos de acesso à educação de qualidade), pela segmentação do mercado de trabalho e pela discriminação de gênero e de etnia (Lustig, Lopez-Calva e Juarez-Ortiz, 2013, p. 129). Quando grupos poderosos que concentram a riqueza monopolizam a formulação de políticas governamentais, as regras curvam-se em favor deles, em detrimento da maioria da população. As consequências não poderiam ser outras senão a erosão da governança democrática, a redução da coesão social e o desaparecimento de oportunidades para todos.

O papel da elite predatória se manifesta quando confrontada com crises econômicas e políticas. O temor com as potenciais consequências dessas crises a obriga a redirecionar sua atenção de atividades produtivas para uma economia de saque (economia da pilhagem). Nesse tipo de economia, a concentração de renda é exacerbada, há um aumento da pobreza e um redesenho das instituições para favorecer os mais influentes. Esses fatores produzem volatilidade e instabilidade política. Tal situação vai ao encontro da avaliação de Nel (2008) sobre os países em desenvolvimento, ao afirmar que a desigualdade econômica influencia negativamente o desenvolvimento econômico, político e humano. Elevados índices de desigualdade, segundo o autor, minam o potencial de crescimento de um país, retardam o desenvolvimento de capital social e da confiança, fomentam a corrupção e o conflito e limitam as oportunidades para o desenvolvimento consistente do regime político. 
Tal situação possibilita que as políticas sociais e econômicas sigam um padrão que pouco se modifica. Se num contexto de mudanças as coisas precisam mudar para que fiquem como estão, conforme a proposição de Lampedusa, então se pode esperar que, num contexto de (re)democratização com inércia, as instituições mudem, sem, no entanto, alterar, numa direção positiva, as normas, os valores e as crenças normativas da população em relação à democracia. Esse ponto de vista vai de encontro a um consenso emergente de que a principal explicação para o desempenho do desenvolvimento entre países ao longo do tempo é a variação entre instituições (Acemoglu e Robinson, 2012; Fukuyama, 2013). Segundo esses autores, países economicamente prósperos se caracterizam por terem instituições políticas inclusivas no sentido de que são centralizadas (instituições detêm um controle suficiente sobre determinadas áreas geográficas) e pluralizadas (existe um acordo sobre a divisão de poder). Em contrapartida, quando as instituições colocam poucos constrangimentos no exercício do poder pela elite, os recursos são extraídos da sociedade em vez de serem utilizados produtivamente (Acemoglu e Robinson, 2012).

Do ponto de vista de uma democracia inercial, pode-se compreender por que, em alguns casos, países emergentes, com crescimento econômico positivo, não conseguem transformar esses recursos em investimentos sociais sólidos, produzindo frustração nos cidadãos, a qual se materializa em desconfiança nas instituições políticas e na política em geral. É fundamental, portanto, problematizar como o crescimento econômico com estagnação (ou aumentos nominais) em investimentos sociais, associado a percepções negativas, hostis e de desconfiança nas instituições políticas por parte dos cidadãos, produz desconfiança institucional, contribuindo para criar uma "inércia democrática".

Argumentamos que essa situação foi gerada pela lógica de natureza convencional (institucional), subjacente ao pensamento político hegemônico, o qual não se direciona para a promoção da estabilidade política dos países em desenvolvimento, pois negligencia os interesses majoritários, favorecendo o atendimento dos interesses das elites e dos grupos poderosos. Contribui, nesse sentido, para manter a maioria dos cidadãos numa situação de desempoderamento político. O resultado é a vulnerabilidade política dos cidadãos diante da soberania doméstica do Estado, de suas instituições e de seus representantes, uma vez que os governos não adotam os mecanismos necessários para fomentar a constituição de uma cultura política participativa e assertiva.

O quadro discutido acima se aplica também ao caso do Brasil, onde uma cultura política pouco participativa e a prevalência da desigualdade são características históricas de sua sociedade, conforme se discute a seguir. 


\section{Cultura política no Brasil}

Há um consenso atualmente a respeito de que a construção do imaginário coletivo dos cidadãos sobre a democracia no Brasil é afetada pelo desempenho econômico. O caso de uma economia estagnada ou que fracassa em resolver a dívida social gera descrença nas pessoas a respeito das bases da democracia representativa, que se manifesta em protestos e abominação pela política e suas instituições. Os cidadãos passam a exigir um sistema político não só mais eficiente, mas, sobretudo, que ofereça uma distribuição mais equitativa da riqueza que modelos tradicionais populistas e tecnocráticos não têm conseguido. Esse tem sido um padrão histórico da evolução político-econômica do Brasil.

A influência de determinados padrões culturais, usos e costumes no funcionamento das instituições políticas brasileiras foi destacada por diferentes autores, como Holanda (1966), Leal (2012), Faoro (1973) e Da Matta (1979). Elementos como a predominância de padrões que valorizam o contato pessoal, o patrimonialismo e o clientelismo são apontados como heranças do passado colonial português que permanecem presentes na sociedade brasileira, apesar dos processos de modernização ocorridos ao longo do século XX.

Os estudos de cultura política no país desenvolveram-se entre a década de 1980 e a de 1990 com o processo de democratização e a possibilidade da realização de surveys regionais e nacionais que fundamentaram os trabalhos pioneiros de Moisés (1995), Baquero (1989, 1994) e Lamounier e Souza (1991). Passou-se da percepção subjetiva, baseada em observação pessoal e descrição da trajetória histórica, para estudos de natureza empírica, baseados na análise de valores e atitudes da população.

Passados 30 anos do retorno à democracia e à administração civil, a proliferação de pesquisas periódicas sobre comportamento político disponibiliza, hoje, para o pesquisador, diferentes bases de dados que permitem estudos de natureza diacrônica. Com diferentes fontes de informação, os autores que analisam a cultura política nessas últimas décadas têm chegado a conclusões semelhantes. Ribeiro (2007), utilizando dados do World Values Survey - WVS (Pesquisa Mundial De Valores), Baquero e González (2011), com base em dados do Eseb, e González (2014), com dados do Latinobarômetro, convergem à análise de que o período democrático não teve um efeito de socialização nas novas gerações para o desenvolvimento de valores e atitudes mais favoráveis à democracia.

Por outro lado, Moisés e Meneguello (2013) e Baquero (2012) observam a manutenção de baixos níveis de confiança nas instituições representativas. A cultura política brasileira é caracterizada como híbrida, com valores democráticos e aceitação de práticas autoritárias. Análises centradas em uma perspectiva institucional discrepam ao considerar que o modelo brasileiro seria funcional e estável (o presidencialismo de coalizão). 
Fato preocupante revelado por essas pesquisas diz respeito à existência de parcela importante da população que considera aceitável a intervenção dos militares na política. O Brasil é o país no continente com o maior percentual de cidadãos que consideram outras possibilidades de regime além da democracia (González, 2014).

Baixos níveis de apoio abstrato à democracia não são um fenômeno exclusivo do Brasil, como constatado por Dalton (1999) e Norris (1999). No entanto, os autores discordam que esse fenômeno represente um perigo para a democracia.

Norris (1999) defende o caráter multidimensional do apoio às instituições, separando diferentes objetos. O declínio do apoio a determinadas instituições poderia representar o surgimento de cidadãos críticos. Montero, Gunther e Torcal (1999) identificam o fenômeno da desafeição, convivendo com altos níveis de apoio abstrato à democracia, com baixa confiança em instituições representativas. Dalton (2008) considera que não existe um perigo para a democracia nos EUA, mas a emergência de uma nova concepção de cidadania, não baseada apenas no seguimento das regras. Esses autores centram sua análise em países com economias desenvolvidas e alto nível de consenso social sobre a manutenção das instituições. Esse não parece ser o caso brasileiro.

A seguir, são analisados os dados das pesquisas do Eseb referentes ao período 2002-2014, verificando-se como evoluiu a avaliação dos brasileiros em relação à democracia e seus instrumentos, paralelamente à análise das mudanças econômicas nesse período.

\section{Economia e cultura política no Brasil no século XXI}

Nos últimos 40 anos, o Brasil sofreu profundas transformações políticas, passando por uma transição iniciada nos anos 1970 para um governo civil em 1985, consolidando-se a democracia com uma nova Constituição em 1988 e eleições diretas para presidente em 1989.

Nesse período, no entanto, as mudanças no campo econômico foram muito mais lentas. Como se pode se verificar no Gráfico 1, a grande concentração de renda entre os mais ricos permaneceu praticamente inalterada nas primeiras três décadas, passando a ter uma redução moderada, mas constante, na última década. 


\section{Gráfico $1^{2}$
Renda e pobreza no Brasil (1976-2014)}

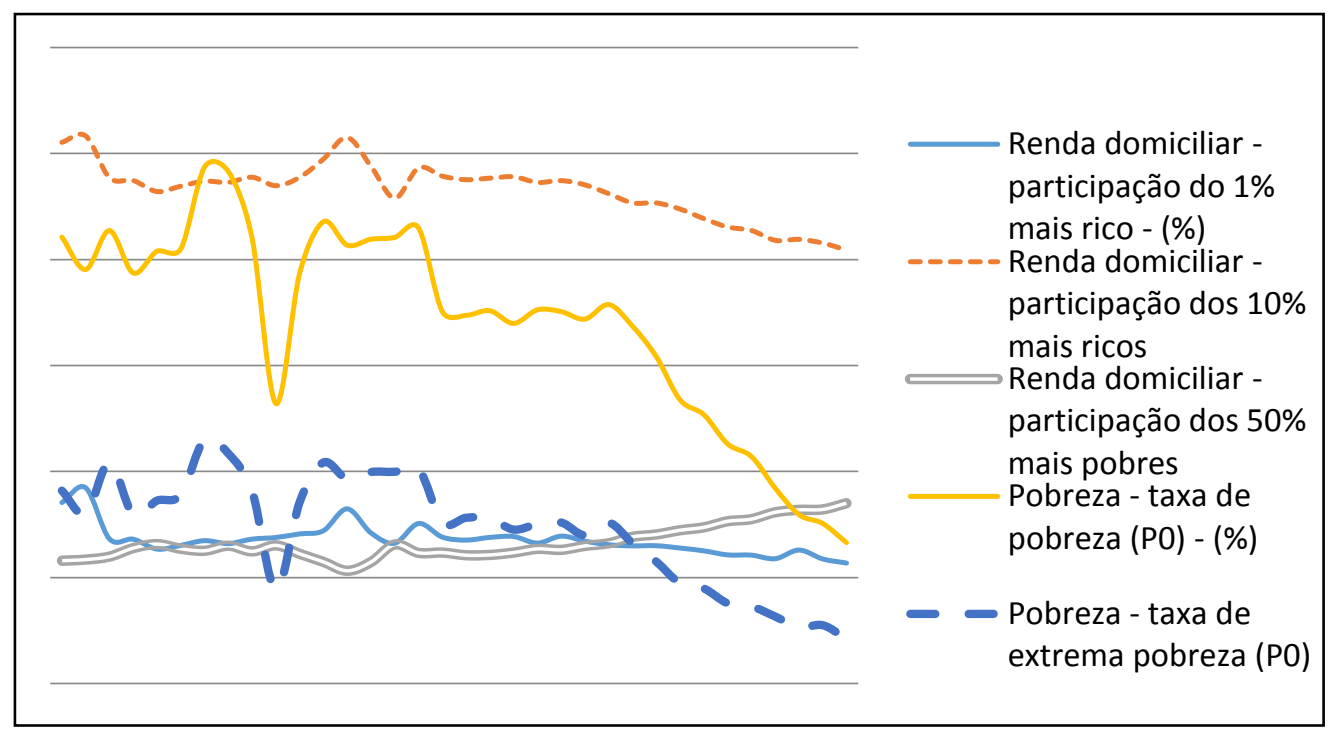

Fonte: Ipeadata, 2016.

Com relação às taxas de pobreza, percebe-se um efeito das políticas econômicas ao longo do período - uma redução acentuada dessas taxas com o Plano Cruzado, com retorno aos patamares anteriores quando a inflação volta a subir e uma redução estabilizada após o Plano Real, demonstrando os efeitos da inflação sobre a pobreza. Porém, após a estabilização da moeda, os percentuais de pobreza permanecem estáveis, somente voltando a cair de forma continuada a partir do início do governo Lula, sendo um indicativo de sucesso dos programas de transferência de renda.

A partir do Plano Real, o percentual de participação dos $50 \%$ mais pobres na renda total do país tem crescido continuamente, superando o percentual do $1 \%$ mais rico em 2003. No entanto, permanece pequena a diferença da renda entre os dois grupos. Se fossem mantidas as tendências desse período, o que pode estar em perigo com a atual crise política e econômica, ainda seria necessário mais de duas décadas para os $50 \%$ mais pobres alcançarem o mesmo percentual da renda dos $10 \%$ mais ricos.

Porém, se levarmos em conta que a pobreza aqui é medida pela metodologia da FAO, pelo acesso ao número de calorias mínimo, ao lado dos dados sobre distribuição de

\footnotetext{
${ }^{2}$ Os dados completos utilizados neste gráfico estão disponíveis no Anexo (cinco primeiras colunas da tabela).
} 
renda, verifica-se que a melhoria das condições de consumo da população mais pobre não foi feita à custa da renda dos mais ricos, que, embora tenha decaído em sua participação percentual na renda nacional, cresceu do ponto de vista absoluto.

Como se pode verificar na Tabela 1 , na primeira década e meia do século XXI, embora a renda média da população tenha crescido mais do que a do $1 \%$ mais rico, a renda da população total não chegou a $9 \%$ da renda média dos mais ricos.

Tabela 1

Renda média da população

\begin{tabular}{|l|c|c|c|c|c|c|}
\hline & $\mathbf{2 0 0 2}$ & $\mathbf{2 0 0 3}$ & $\mathbf{2 0 0 4}$ & $\mathbf{2 0 0 5}$ & $\mathbf{2 0 0 6}$ & $\mathbf{2 0 0 7}$ \\
\hline $1 \%$ mais rico & $9.641,97$ & $8.848,62$ & $8.973,22$ & $9.522,75$ & $10.231,84$ & $10.284,77$ \\
\hline Toda a população & 718,34 & 676,51 & 691,55 & 733,08 & 801,27 & 822,47 \\
\hline$\%$ & 7,4 & 7,6 & 7,7 & 7,7 & 7,8 & 8,0 \\
\hline & $\mathbf{2 0 0 8}$ & $\mathbf{2 0 0 9}$ & $\mathbf{2 0 1 1}$ & $\mathbf{2 0 1 2}$ & $\mathbf{2 0 1 3}$ & $\mathbf{2 0 1 4}$ \\
\hline $1 \%$ mais rico & $10.457,57$ & $10.718,27$ & $11.073,70$ & $12.781,87$ & $12.298,69$ & $13.075,90$ \\
\hline Toda a população & 862,63 & 885,83 & 941,60 & $1.016,32$ & $1.047,95$ & $1.152,24$ \\
\hline$\%$ & 8,2 & 8,3 & 8,5 & 8,0 & 8,5 & 8,8 \\
\hline
\end{tabular}

Fonte: Ipea, Ipeadata, 2016. Reais (R\$) de outubro 2013.

Por outro lado, em termos absolutos, a pobreza também chama a atenção. Ainda que com os percentuais de redução constantes, restavam, em 2014, cerca de 8 milhões de pessoas em extrema pobreza e 25 milhões de pobres.

A taxa de desemprego, que teve uma queda importante a partir de 2009, voltou a crescer em 2013 (IBGE, 2016), ainda que se mantenha em patamares inferiores aos do início da década anterior. A inflação voltou a subir em 2015 , passando de $10 \%$, o que não ocorria desde 2003 (ver Anexo, ao final).

O cenário aponta dificuldades econômicas nos próximos tempos, com possibilidade de redução de gastos públicos. O aumento da inflação, associado ao desemprego, pode provocar uma mudança da tendência de redução da pobreza, tendo em vista que o aumento do custo de vida tende a atingir desproporcionalmente os mais pobres.

A população brasileira, no período de prosperidade, teria construído um maior grau de confiança nas instituições e nos governantes, que permitisse um crédito de confiança para passar pelo período de turbulência? Nossa hipótese é que isso não ocorreu.

Diversos autores identificam a manutenção de baixos níveis de confiança em instituições representativas, tais como partidos e Congresso, no caso brasileiro. Ao mesmo tempo, os níveis de satisfação com o regime também permanecem baixos. 
O distanciamento da população em relação ao sistema político tende a ser explicado pela incapacidade do Estado de resolver problemas históricos como a manutenção de altos níveis de desigualdade. No entanto, nas últimas duas décadas, tem havido uma melhora constante de diversos indicadores sociais. Essa mudança não tem impactado na mesma medida a percepção das instituições.

Alguns dados econômicos selecionados de um período entre o final do governo Fernando Henrique Cardoso e o final do primeiro mandato de Dilma Rousseff indicam, em geral, resultados positivos em aspectos como diminuição de níveis de pobreza e desigualdade, aumento da expectativa de vida e aumento da renda per capita, em um período que ainda não se sentia a deterioração de fatores econômicos hoje existentes.

Em alguns casos, a evolução é lenta, como a queda do percentual de renda do $1 \%$ e dos $10 \%$ mais ricos, que ainda mostra uma extrema desigualdade de renda no país. Em outros casos, como a inflação, já se percebia, no ano passado, uma retomada do crescimento dos preços, ainda que em percentuais que hoje são menores do que no último ano do governo FHC. A taxa de desemprego, embora tenha aumentado, ainda está em patamar menor do que no início da década anterior.

Porém, como fica a percepção da população em relação às instituições políticas nesse período? São analisadas, a seguir, as diferentes dimensões, desde o apoio abstrato ao regime, passando pela avaliação das instituições e dos governantes.

Quanto ao apoio difuso à democracia, avaliamos o comportamento de duas variáveis. Na questão formulada, se em algumas situações a ditadura é melhor, houve certa queda do percentual que apoia a ditadura. No entanto, se considerarmos os que dizem que tanto faz, como os que se posicionam como não sabendo, o percentual não baixou de $25 \%$ no período e, em 2014 , era ligeiramente maior do que em 2002, acima de $30 \%$ (Tabela 2).

Embora o percentual dos que consideram a democracia como a melhor forma de governo tenha sido sempre predominante, um percentual de cerca de um terço da população que aceita o autoritarismo ou é indiferente não pode ser considerado um mero traço minoritário da cultura política, mas um elemento relevante de fragilidade do apoio ao regime. 
Tabela 2

Opinião sobre a democracia (\%)

\begin{tabular}{|l|c|c|c|c|}
\hline Ano & $\mathbf{2 0 0 2}$ & $\mathbf{2 0 0 6}$ & $\mathbf{2 0 1 0}$ & $\mathbf{2 0 1 4}$ \\
\hline $\begin{array}{l}\text { Em algumas situações é melhor uma ditadura do que uma } \\
\text { democracia }\end{array}$ & 18,7 & 14,2 & 8,2 & 10,3 \\
\hline Tanto faz / Nenhuma das duas é melhor & 2,4 & 6,9 & 5,3 & 7,9 \\
\hline Não sabe & 9,3 & 7,1 & 8,0 & 16,0 \\
\hline Subtotal & $\mathbf{3 0 , 4}$ & $\mathbf{2 8 , 2}$ & $\mathbf{2 1 , 5}$ & $\mathbf{3 4 , 1}$ \\
\hline A democracia é sempre melhor que outra forma de governo & 68,8 & 71,4 & 78,4 & 64,0 \\
\hline Não respondeu & 0,9 & 0,5 & 0,2 & 1,9 \\
\hline Total & 100,0 & 100,0 & 100,0 & 100,0 \\
\hline
\end{tabular}

Fonte: Eseb, 2002-2014.

Quando a questão formulada parte da afirmação de que a democracia tem alguns problemas, mas é a melhor forma de governo, o percentual dos que não manifestam concordância com a afirmação ficou próximo dos $20 \%$ durante a década, passando de $30 \%$ em 2014, com um crescimento efetivo dos que afirmam não ter posição, não concordando nem discordando (Tabela 3).

Tabela 3

Opinião sobre: a democracia tem alguns problemas, mas é melhor do que qualquer outra forma de governo $(\%)$

\begin{tabular}{|l|c|c|c|c|}
\hline Ano & $\mathbf{2 0 0 2}$ & $\mathbf{2 0 0 6}$ & $\mathbf{2 0 1 0}$ & $\mathbf{2 0 1 4}$ \\
\hline Nem concorda nem discorda & 1,8 & 14,8 & 7,4 & 17,5 \\
\hline Discorda um pouco & 7,1 & 4,3 & 2,6 & 4,7 \\
\hline Discorda muito & 5,0 & 0,9 & 2,0 & 3,7 \\
\hline Não sabe & 8,3 & 4,2 & 5,1 & 5,9 \\
\hline Subtotal & $\mathbf{2 2 , 1}$ & $\mathbf{2 4 , 2}$ & $\mathbf{1 7 , 0}$ & $\mathbf{3 1 , 7}$ \\
\hline Concorda um pouco & 26,0 & 33,8 & 24,4 & 34,5 \\
\hline Concorda muito & 51,2 & 41,5 & 58,5 & 37,8 \\
\hline Não respondeu & 0,6 & 0,5 & 0,2 & 0,7 \\
\hline Total & 100,0 & 100,0 & 100,0 & 100,0 \\
\hline
\end{tabular}

Fonte: Eseb, 2002-2014.

${ }^{3}$ Nota para todas as tabelas com referência aos dados do Eseb: $2002 \mathrm{n}=2513 ; 2006 \mathrm{n}=1000 ; 2010 \mathrm{n}=$ $2000 ; 2014 \mathrm{n}=2506$. 
Também para essa variável a posição dominante é a pró-democrática. No entanto, esse percentual oscilou no período, caindo de 82,9\% para 72,3\% entre 2010 e 2014, com o aumento dos que ficam indiferentes. Há uma consistência na medida das duas variáveis com a existência de um percentual relevante de respondentes com uma posição potencialmente autoritária ou apática.

Passando para uma avaliação mais concreta do regime, os níveis de satisfação com a democracia são bastante menores que o apoio abstrato ao regime (Tabela 4).

Tabela 4

Nível de satisfação com o funcionamento da democracia no Brasil

\begin{tabular}{|l|c|c|c|c|}
\hline Ano & $\mathbf{2 0 0 2}$ & $\mathbf{2 0 0 6}$ & $\mathbf{2 0 1 0}$ & $\mathbf{2 0 1 4}$ \\
\hline Muito satisfeito(a) & 5,0 & 4,1 & 7,7 & 4,2 \\
\hline Satisfeito(a) & 25,3 & 38,6 & 40,3 & 34,7 \\
\hline Nem satisfeito(a) nem insatisfeito(a) & 1,8 & 11,6 & 17,5 & 20,6 \\
\hline Pouco satisfeito(a) & 35,1 & 26,7 & 21,2 & 21,8 \\
\hline Nada satisfeito(a) & 25,8 & 14,3 & 8,9 & 14,3 \\
\hline Não sabe & 4,8 & 4,3 & 4,4 & 4,2 \\
\hline Não respondeu & 1,7 & 0,4 & 0,2 & 0,3 \\
\hline Total & 100,0 & 100,0 & 100,0 & 100,0 \\
\hline
\end{tabular}

Fonte: Eseb, 2002-2014.

Enquanto, em 2002, o nível de insatisfação passou de $60 \%$, caindo nos anos posteriores, o percentual dos satisfeitos, embora tenha aumentado ao longo do período, nunca alcançou $50 \%$, sendo que os muito satisfeitos não chegam, em nenhum dos anos, a $10 \%$, com um crescimento expressivo dos que não se consideravam nem satisfeitos nem insatisfeitos.

Isso significa que, mesmo em 2010, com um alto grau de aprovação do governo do presidente Lula, com 93,2\% dos entrevistados considerando a atuação do presidente, nos últimos quatro anos, muito boa ou boa, menos da metade da população se manifestava satisfeita com a democracia.

No período compreendido entre as quatro eleições, há a manutenção de uma avaliação de importância do processo político. O percentual de pessoas que consideram que não faz diferença quem governa o país se reduziu para menos de $10 \%$, ficando em $7,5 \%$ em 2014, ao mesmo tempo em que o percentual dos que dizem que faz grande diferença caiu de $67,6 \%$ para $58,7 \%$, mas permanece próximo aos patamares do início da década anterior (Tabela 5). 
Tabela 5

Influência de quem governa o Brasil (\%)

\begin{tabular}{|c|c|c|c|c|}
\hline Ano & 2002 & 2006 & 2010 & 2014 \\
\hline Faz uma grande diferença quem governa o país & 56,2 & 62,3 & 67,6 & 58,7 \\
\hline Faz diferença quem governa o Brasil & 14,7 & 15,5 & 13,4 & 19,7 \\
\hline É indiferente quem governa o Brasil & 12,8 & 10,4 & 8,1 & 13,6 \\
\hline Não faz diferença quem governa o Brasil & 3,7 & 2,4 & 3,6 & 2,9 \\
\hline Não faz nenhuma diferença quem governa o Brasil & 9,4 & 7,9 & 6,0 & 4,6 \\
\hline Não sabe & 2,7 & 1,4 & 1,2 & 1,3 \\
\hline Não respondeu & 0,5 & 0 & 0,2 & 0,2 \\
\hline Total & 100,0 & 100,0 & 100,0 & 100,0 \\
\hline
\end{tabular}

Fonte: Eseb, 2002-2014.

A avaliação de importância do voto permaneceu relativamente estável, com a soma dos que consideram que o voto influencia muito ou um pouco próxima de $80 \%$. Ao mesmo tempo, o percentual dos que dizem que o voto não influencia o que acontece no país baixou alguns pontos, ficando em 8,1\% em 2014 (Tabela 6).

Tabela 6

Influência do voto no que acontece no Brasil (\%)

\begin{tabular}{|c|c|c|c|c|}
\hline Ano & 2002 & 2006 & 2010 & 2014 \\
\hline Nosso voto influencia muito no que acontece no Brasil & 63,8 & 64,7 & 71,3 & 61,2 \\
\hline Nosso voto influencia pouco no que acontece no Brasil & 13,3 & 11,5 & 11,7 & 17,5 \\
\hline É indiferente & 8,5 & 11,7 & 7,2 & 11,7 \\
\hline Nosso voto não influencia muito no que acontece no Brasil & 3,0 & 2,6 & 2,8 & 3,4 \\
\hline Nosso voto não influencia nada no que acontece no Brasil & 9,1 & 7,7 & 6,3 & 4,7 \\
\hline Não sabe & 1,9 & 1,7 & 0,7 & 1,1 \\
\hline Não respondeu & 0,3 & 0,1 & 0,1 & 0,3 \\
\hline Total & 100,0 & 100,0 & 100,0 & 100,0 \\
\hline
\end{tabular}

Fonte: Eseb, 2002-2014.

A avaliação da importância do voto, apresentada na Tabela 6, levaria a supor que as pessoas estivessem dispostas a votar. Porém, voltou a crescer o número de pessoas que afirmam que não votariam se o voto não fosse obrigatório, ultrapassando o percentual dos que votariam. É contraditório que as pessoas considerem que faz diferença quem 
governa o país e que o voto influencia o que acontece no país, mas não estejam necessariamente dispostas a participar (Tabela 7).

Tabela 7

Votaria caso o voto não fosse obrigatório

\begin{tabular}{|l|c|c|c|c|}
\hline Ano & $\mathbf{2 0 0 2}$ & $\mathbf{2 0 0 6}$ & $\mathbf{2 0 1 0}$ & $\mathbf{2 0 1 4}$ \\
\hline Não & 45,5 & 54,6 & 44,6 & 47,3 \\
\hline Sim & 52,4 & 39,5 & 50,1 & 45,3 \\
\hline Talvez/Depende & 2,1 & 5,9 & 5,3 & 7,4 \\
\hline Total & 100,0 & 100,0 & 100,0 & 100,0 \\
\hline
\end{tabular}

Fonte: Eseb, 2002-2014.

Apesar de a situação econômica, em diversos aspectos, ser melhor em 2014 do que no início dos anos 2000, a percepção da população retoma um viés de desconfiança que aproxima 2014 de 2002. A avaliação da atuação do governo federal caiu em 2014 em relação aos anos anteriores, ainda que a soma das percepções negativas seja menor que os valores de 2002. A percepção negativa do governo Dilma é menor que a presente no final dos governos FHC e no primeiro governo de Lula, distante da popularidade de Lula em 2010, conforme pode ser visto na Tabela 8.

Tabela 8

Avaliação do governo do presidente nos últimos quatro anos

\begin{tabular}{|l|c|c|c|c|}
\hline Ano & $\mathbf{2 0 0 2}$ & $\mathbf{2 0 0 6}$ & $\mathbf{2 0 1 0}$ & $\mathbf{2 0 1 4}$ \\
\hline Ruim & FHC & Lula & Lula & Dilma \\
\hline Péssimo & 27,1 & 17,3 & 4,8 & 13,4 \\
\hline Subtotal & 17,2 & 17,3 & 1,3 & 8,7 \\
\hline Regular & $\mathbf{4 4 , 2}$ & $\mathbf{3 4 , 7}$ & $\mathbf{6 , 1}$ & $\mathbf{2 2 , 1}$ \\
\hline Bom & 14,0 & - & - & 31,4 \\
\hline Muito bom ou Ótimo & 36,2 & 64,6 & 61,7 & 38,1 \\
\hline Não sabe & 3,8 & 10,8 & 31,9 & 7,2 \\
\hline Não respondeu & 1,2 & 0,7 & 0,7 & 0,8 \\
\hline Total & 0,6 & 0,3 & 0,2 & 0,4 \\
\hline
\end{tabular}

Fonte: Eseb, 2002-2014.

A escala utilizada pelo Eseb no período variou, tornando difícil a comparação das posições intermediárias. Porém, é possível perceber as mudanças dos extremos. As avaliações ruim e péssimo do presidente FHC, em 2002, somavam 44,2\%, e ótimo era 
apenas de 3,8\%. Essa posição se inverte no segundo mandato de Lula, que tem 31,9\% de avaliação muito bom e $6,1 \%$ de ruim e péssimo, e volta a se inverter na avaliação de Dilma, com $7,2 \%$ de muito bom e $22,1 \%$ de ruim e péssimo, mas, ainda assim, com uma avaliação melhor que a de Fernando Henrique. Essa mudança de posição da população é corroborada pelo Gráfico 2.

Em geral, os dados indicam que as percepções da política tiveram uma transformação positiva até 2010 e voltaram a patamares semelhantes a 2002 na última eleição. Embora os indicadores econômicos tenham demorado um pouco a mudar, aparentemente a crise econômica que se avizinhava já se fazia sentir no aumento do pessimismo sobre as variáveis de confiança nas instituições políticas. Ou seja, mesmo que alguns indicadores tenham mudado para melhor, a visão de curto prazo da economia afeta a visão de curto prazo da política.

Essa avaliação não tem relação direta com a avaliação dos governantes. Nesse período, houve uma queda dos que consideravam a avaliação do governo anterior ruim ou péssimo, com um aumento no governo Dilma das avaliações ruim ou péssimo. O nível de satisfação com a democracia, embora tenha melhorado ao longo dos governos de Lula, manteve ao menos $30 \%$ de pouco ou nada satisfeitos.

Quando cruzados os dados pelas opções de voto no segundo turno de 2010 e 2014, as variáveis que parecem diretamente afetadas são a satisfação com a democracia e a avaliação do governo Dilma.

O que se percebe no comportamento das diversas variáveis de avaliação institucional não é necessariamente uma posição de defesa direta do autoritarismo, mas uma apatia e um distanciamento, como o descrito no caso espanhol por Montero, Gunther e Torcal (1999).

Se analisarmos o comportamento dessas variáveis ante os indicadores sociais e econômicos no período, verifica-se que há uma ligeira melhora dos indicadores de apoio e satisfação com a democracia no período de melhores resultados econômicos. Porém, tal resultado não é estável, modificando-se junto com a deterioração da situação econômica.

Como pode se verificar pelos dados da pesquisa trimestral da CNI (Confederação Nacional da Indústria) sobre avaliação do presidente e do governo (Gráfico 2), a popularidade do incumbente varia juntamente com a avaliação do governo, ainda que, em geral, exista uma visão mais positiva do governante do que do governo, o que particularmente ocorre durante o primeiro governo de Lula e no início do primeiro governo de Dilma. O único momento em que a avaliação de governo e a do presidente se equivalem, estando nos patamares mais altos, foi no final do segundo mandato de Lula.

Porém, também se verifica, no período recente, que a queda na avaliação positiva pode modificar-se rapidamente, sendo perceptível que a avaliação negativa da presidente Dilma avança em ritmo maior do que a efetiva modificação das condições econômicas, 
chegando, no final de 2015, primeiro ano do segundo mandato, a níveis de confiança inferiores aos de Fernando Henrique Cardoso no final do seu mandato.

\section{Gráfico 2 \\ Avaliação do governo e Confiança no(a) presidente - 1999-2015 (\%)}

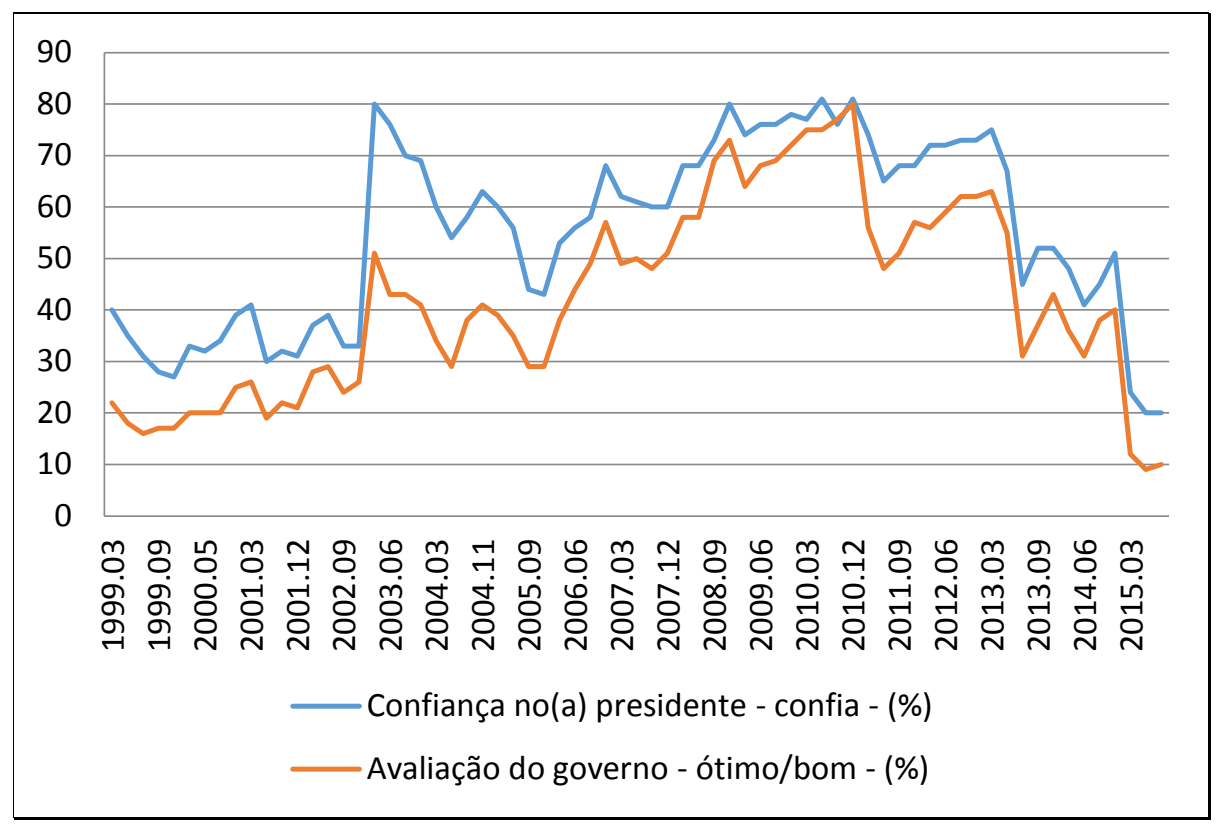

Fonte: Ipea, Ipeadata, 2016 (Confederação Nacional das Indústrias).

Ainda que seja uma impressão apenas parcial do período, o crescimento de uma visão pessimista pode ser verificado na comparação entre 2010 e 2014. Quando questionados sobre a situação do país no último ano, mais de metade dos entrevistados em 2010 considerava que estava melhor. Em 2014, apenas 24,1\% consideravam que estava melhor, com um percentual maior, de $27,7 \%$, avaliando que estava pior. Ou seja, nem ao menos todos os eleitores de Dilma consideravam que o país estava melhorando (Tabela 9). 
Tabela 9

Situação econômica atual do país está melhor, igual ou pior que há 12 meses? (\%)

\begin{tabular}{|l|c|c|}
\hline Ano & $\mathbf{2 0 1 0}$ & $\mathbf{2 0 1 4}$ \\
\hline Melhor & 53,1 & 24,1 \\
\hline Igual & 38,1 & 45,9 \\
\hline Pior & 5,3 & 27,7 \\
\hline Não sabe/Não respondeu & 3,6 & 2,3 \\
\hline Total & 100,0 & 100,0 \\
\hline
\end{tabular}

Fonte: Eseb, 2002-2014.

De forma geral os dados de percepção sobre o sistema político tiveram alterações, sob a forma de oscilações entre momentos de maior otimismo, como em 2002 e 2010, e de maior pessimismo, em 2006 e 2014. O padrão de crescimento econômico e de melhoria de indicadores sociais parece ter impactado mais a popularidade dos governantes do que a confiança ou a satisfação com as instituições.

\section{Conclusões}

$\mathrm{Na}$ última década, sucederam-se quatro governos liderados pelo Partido dos Trabalhadores, dois em que foi eleito Luiz Inácio Lula da Silva e dois liderados por Dilma Rousseff, com o segundo mandato interrompido.

Na primeira década do século, as condições econômicas favoráveis permitiram ao país níveis razoáveis de crescimento, que lhe valeram a inclusão dentro do bloco das economias emergentes (Brics). A adoção de programas governamentais contribuiu para a redução dos níveis absolutos de pobreza.

O Brasil, nesse período, não conseguiu consolidar uma cultura política predominantemente democrática, sendo presente um percentual grande de cidadãos que se mostram ambivalentes em relação à democracia (Moisés, 2008). A realização de eleições não parece ter tido um efeito de socialização no sentido de fortalecer o apoio com a democracia (Baquero e González, 2011).

Se, conforme algumas perspectivas teóricas, o temporário êxito econômico e a estabilidade institucional vivida na última década e meia deveriam ter permitido o desenvolvimento e a consolidação de valores democráticos, com um apoio robusto ao regime e às instituições e níveis razoáveis de satisfação, os dados apresentados parecem indicar o contrário.

Esse cenário positivo faz parte do passado, com o país vivendo, hoje, uma recessão, com cortes em gastos sociais e baixa da popularidade tanto da presidente afastada como 
do atual ocupante do cargo. O personalismo da política brasileira faz com que a identificação com os incumbentes seja um fator primordial. A estabilidade do regime está ancorada na popularidade dos dirigentes políticos e esta, por sua vez, estreitamente ligada à capacidade de garantir a execução de políticas que tragam benefícios individualizados aos diferentes setores da população.

Poderíamos argumentar que tal deterioração é resultado da percepção dos escândalos de corrupção. Porém, a divulgação de fatos dessa natureza não é um elemento novo na política brasileira. Cabe lembrar que a exposição do mecanismo de compra de apoios no Congresso Nacional, intitulado pela mídia de "Mensalão", não impediu que houvesse a reeleição do presidente Lula e que este viesse a alcançar os mais altos níveis de popularidade no segundo mandato.

Da mesma forma, o julgamento dos acusados naquele caso, com a intensa exploração pública da condenação do ex-ministro da casa civil José Dirceu, também não foi suficiente para impedir a reeleição de Dilma, indicando uma separação entre a avaliação dos governantes e as acusações contra o partido. Os escândalos que são rapidamente esquecidos em tempos de bonança não são tolerados nos momentos de crise, tanto que os principais argumentos utilizados pela oposição na defesa ao público do processo de afastamento de Dilma estavam mais centrados na incapacidade do governo de fazer o enfrentamento dos problemas econômicos do que nas ilegalidades cometidas, que foram mero pretexto formal para abrir o procedimento.

A exposição pela mídia de uma situação econômica adversa parece ter desencadeado rapidamente uma percepção de pessimismo que afeta a avaliação das instituições. O período de bonança não parece ter criado atitudes favoráveis e arraigadas para com a democracia e suas instituições.

A rápida deterioração da avaliação tanto do governo como da presidente indica que a avaliação negativa de pouco mais de $20 \%$ dos entrevistados em relação ao mandato do governo passado, mesmo com o efetivo resultado de redução da pobreza e do desemprego no período, não gerou uma tolerância a ser explorada no novo mandato. Em poucos meses, o possível crédito de confiança desapareceu.

A posição da população ante as instituições democráticas e os governantes tende a variar em função de sua satisfação material. Crise econômica e crise de popularidade dos líderes políticos são fatores de desestabilização do regime. Assim, consideramos que há indicativos da presença de um componente inercial na percepção negativa de partes da população com relação às instituições e à democracia, que não tem se alterado nem com resultados econômicos nem com as sucessivas eleições. A menos que esse componente possa ser modificado, seja com o desenvolvimento de políticas econômicas que garantam crescimento e redução da pobreza de forma sustentada, seja com o empoderamento da população e o desenvolvimento de valores participativos, a perspectiva é de que a 
democracia brasileira continue anêmica e sofrendo periódicos eventos de intranquilidade, em outras palavras, uma democracia inercial.

Marcello Baquero - Doutor em ciência política pela Florida State University. Com pósdoutorado pelo Instituto Gino Germani da Universidade de Buenos Aires, Argentina, e pela Universidade de Sussex, Inglaterra. Professor titular do Departamento de Ciência Política da Universidade Federal do Rio Grande do Sul. E-mail: <marcelo.baquero@ufrgs.br>.

Rodrigo Stumpf Gonzále - Doutor em ciência política pela Universidade Federal do Rio Grande do Sul. Professor adjunto do Departamento de Ciência Política da Universidade Federal do Rio Grande do Sul. E-mail: <rodrigo.stumpf@ufrgs.br>.

\section{Referências bibliográficas}

ACEMoglu, D.; RoBinson, J. Why nations fail: the origins of power, prosperity, and poverty. New York: Crown Business, 2012.

ALMOND, G.; VeRBA, S. The civic culture: political attitudes and democracy in five nations. Newbury Park: Sage, 1989.

AltimiR, O. "Cambios de la desigualdad y la pobreza en la América Latina". El Trimestre Económico, nº 241, p. 85-113, 1994.

BAQUero, M. Democracia, partidos e cultura política na América Latina. Porto Alegre: Nupesal/Kuarup, 1989.

Os desafios na construção de uma cultura política democrática na América Latina: Estado e partidos políticos. In: BAQUero, M. (org.). Cultura política e democracia: os desafios das sociedades contemporâneas. Porto Alegre, UFRGS, p. 26-41, 1994.

48, p. 84-92, 2012.

BAquero, M.; GonzÁLez, R. "Eleições, estabilidade democrática e socialização política no Brasil: análise longitudinal da persistência de valores nas eleições presidenciais de 2002 a 2010". Opinião Pública, Campinas, vol. 17, n² 2, p. 369-399, 2011.

BAQUeRo, M.; MoRAIS, J. A. "Desigualdade e democracia na América Latina: o papel da inércia na construção de uma cultura política democrática". In: I Seminário Internacional de Ciência Política, Porto Alegre. Anais I SICP, p. 1-25, 2015.

BARRo, R. J. "Determinants of democracy". Journal of Political Economy, vol. 107, no 6, p. 158-183, 1999.

BoIX, C.; Stokes, S. "Endogenous democratization". World Politics, vol. 55, p. 517-549, 2003.

BRESSER-PeReIRA, L. C. Macroeconomia da estagnação: crítica da ortodoxia convencional no Brasil pós1994. São Paulo: Editora 34, 2007. 
BURCHARDT, H. J. ¿Democracia desigual o desigualdad democrática? Un acercamiento teórico a la realidad socio-política de América Latina. In: KRON, S.; CosTA, S.; BRAIG, M. (eds.). Democracia y reconfigures contemporizas del derecho en América Latina. Madrid/Frankfurt: Vervuert, p. 73-90, 2012.

BRASIL. IBGE. Instituto Brasileiro de Geografia e Estatística. Pesquisa Mensal de Emprego. Disponível em:

<http://www.ibge.gov.br/home/estatistica/indicadores/trabalhoerendimento/pme_nova/defaulttab_his t.shtm>. Acesso em 2 mar. 2016.

BrASIL. IPEA. Instituto de Pesquisa Econômica Aplicada. Banco de dados econômicos e sociais. Disponível em: <http://www.ipeadata.gov.br/>. Acesso em: 2 mar. 2016.

DA MATTA, R. Carnavais, malandros e heróis: para uma sociologia do dilema brasileiro. Rio de Janeiro: Rocco, 1979.

DALton, R. J. Political support in advanced industrial. Oxford: Oxford University Press, 1999.

. "Citizenship norms and the expansion of political participation". Political Studies, vol. 56, n 1, p. 76-98, 2008.

FAORO, R. Os donos do poder: formação do patronato político brasileiro. São Paulo: Globo, 1973.

FuchS, D.; Klingemann, H.-D. (orgs.). Citizens and the State. Oxford: OUP Oxford, 1995.

FUKUYAMA, Francis. "Democracy and the quality of the State". Journal of Democracy. Washington, vol. $24, n^{\circ} 4$, p. 5-16, out. 2013.

GonzÁlez, F. E. Creative destruction? Economic crisis and democracy in Latin America. Baltimore. John Hopkins University Press, 2012.

GonzÁLEZ, R. "Qualidade da democracia, eleições presidenciais e apoio à democracia na América Latina". Temas y Debates, vol. 28, p. 13-28, 2014.

Helliwell, J. F. "Empirical linkages between democracy and economic growth". British Journal of Political Science, vol. 24, n² 2, p. 225-248, 1994.

HolandA, S. B. Raízes do Brasil. Rio de Janeiro: José Olympio, 1966.

Houle, C. "Inequality and democracy: why inequality harms consolidation but does not affect democratization". World Politics, Princeton, vol. 61, n 4, p. 589-622, out. 2009.

Huntington, S. P. Political order in changing societies. New Haven: Yale University Press, 1968.

. A terceira onda: a democratização no final do século XX. São Paulo: Ática, 1994.

InglehaRt, R.; Welzel, C. Modernização, mudança cultural e democracia. São Paulo: Verbena, 2009.

LAMOUNIER, B.; SouZA, A. "Democracia e reforma institucional no Brasil: uma cultura política em mudança". Dados, vol. 34, n³, p. 311-348, 1991.

LEAL, V. N. Coronelismo, enxada e voto. São Paulo: Companhia das Letras, 2012. 
MARCELLO BAQUERO; RODRIGO STUMPF GONZÁLEZ

LIPSET; S. M. "Some social requisites of democracy: economic development and political legitimacy". Denton, vol. 53, n 1, p. 69-105, mar. 1959.

Lustig, N.; Lopez-Calva, L.; Juarez-Ortiz, E. "Inequality in Latin America in the 2000s: the cases of Argentina, Brazil, and Mexico". World Development, vol. 44, p. 129-141, 2013.

MoISÉs, J. Á. Os brasileiros e a democracia: bases sócio-políticas da legitimidade democrática. São Paulo: Ática, 1995.

. "Cultura política, instituições e democracia: lições da experiência brasileira". Revista Brasileira de Ciências Sociais, vol. 23, nº 66, p. 11-43, 2008.

Moisés, J. Á; Meneguello, R. (org.). A desconfiança política e os seus impactos na qualidade da democracia. São Paulo: Edusp, 2013.

MONTERO, J.; GUNTHER, R.; TORCAL, M. "Legitimidad, descontento y desafección". Estudios Públicos, Santiago, vol. 74, 1999.

Moore, B. As origens sociais da democracia e da ditadura. Lisboa/Santos: Edições Cosmos/Livraria Martins Fontes, 1967.

NEL, P. The politics of economic inequality in developing countries. New York: Palgrave McMillian, 2008.

NORRIS, P. (ed.). Critical citizens: global support for democratic government. Oxford: Oxford University Press, 1999.

O'CAMPO, J. A.; Malagõn, J. "Los efectos distributivos de la política fiscal en América Latina". Pensamiento Iberoamericano, $\mathrm{n}^{\circ}$ 10, 2009.

Perez-Liñán, A.; Mainwaring, S. Democratic breakdown and survival in Latin America, 1945-2005. In: BRINKS, D.; LeIRAS, M.; MAINWARING, S. (eds.). Reflections on uneven democracies: the legacy of Guillermo O 'Donnell. Baltimore: John Hopkins University Press, p. 21-43, 2014.

PrZeWORSKI, A.; CheibuB, J. A.; Limongi, F. "Democracia e cultura: uma visão não culturalista". Lua Nova, vol. 58, p. 9-36, 2003.

PRZEWORSKI, A., et al. Democracy and development: political institutions and material well-being in the world, 1950-1990. Cambridge: Cambridge University Press, 2000. Disponível em: <http://books.google.co.uk/books?id=8uocGVOfptMC>. Acesso em: 2 mar. 2016.

Ribeiro, E. A. "Cultura política, instituições e experiência democrática no Brasil". Revista de Sociologia e Política, vol. 28, p. 205-219, 2007.

Rosanvallon, P. Counter-democracy. Politics in an age of distrust. Cambridge: Cambridge University Press, 2008.

Rostow, W. W. The stages of economic growth: a Non-Communist Manifesto. Cambridge: Cambridge University Press, 1960.

Rueschemeyer, D.; Stephens, E. H.; Stephens, J. D. Capitalist development and democracy. Chicago: University of Chicago Press, 1992.

VILAS, C. M. Participation, inequality, and the whereabouts of democracy. In: CHALMERS, D., et al. The new politics of inequality in Latin America. Rethinking participation and representation. Oxford: Oxford University Press, p. 3-43, 1997. 


\section{ANEXO}

Dados econômicos do Brasil (\%)

\begin{tabular}{|c|c|c|c|c|c|c|c|}
\hline Ano & $\begin{array}{c}\text { Renda } \\
\text { domiciliar: } \\
\text { participação } \\
\text { do } 1 \% \text { mais } \\
\text { rico }\end{array}$ & $\begin{array}{c}\text { Renda } \\
\text { domiciliar: } \\
\text { participa- } \\
\text { ção dos } \\
10 \% \text { mais } \\
\text { ricos } \\
\end{array}$ & $\begin{array}{c}\text { Renda } \\
\text { domiciliar: } \\
\text { participa- } \\
\text { ção dos } \\
50 \% \text { mais } \\
\text { pobres }\end{array}$ & $\begin{array}{c}\text { Pobreza: } \\
\text { taxa de } \\
\text { pobreza } \\
\text { (P0) }\end{array}$ & $\begin{array}{l}\text { Pobreza: } \\
\text { taxa de } \\
\text { extrema } \\
\text { pobreza } \\
\text { (P0) }\end{array}$ & $\begin{array}{c}\text { Taxa de } \\
\text { Desempre- } \\
\text { go }\end{array}$ & $\begin{array}{c}\text { Inflação } \\
\text { INPC }\end{array}$ \\
\hline 1976 & 17,08 & 51,04 & 11,58 & 42,12 & 18,20 & - & - \\
\hline 1977 & 18,47 & 51,64 & 11,68 & 39,06 & 15,99 & - & - \\
\hline 1978 & 13,64 & 47,71 & 11,96 & 42,74 & 20,86 & - & - \\
\hline 1979 & 13,61 & 47,45 & 12,77 & 38,74 & 15,92 & - & - \\
\hline 1981 & 12,67 & 46,40 & 13,14 & 40,79 & 17,25 & - & 93,51 \\
\hline 1982 & 13,02 & 46,91 & 12,70 & 41,00 & 17,80 & - & 100,31 \\
\hline 1983 & 13,47 & 47,38 & 12,51 & 48,73 & 23,02 & - & 177,97 \\
\hline 1984 & 13,19 & 47,27 & 12,99 & 48,30 & 21,70 & - & 209,12 \\
\hline 1985 & 13,61 & 47,75 & 12,46 & 42,01 & 18,15 & - & 239,05 \\
\hline 1986 & 13,77 & 46,95 & 13,02 & 26,41 & 8,80 & - & 59,20 \\
\hline 1987 & 14,11 & 47,75 & 12,22 & 38,71 & 17,11 & - & 394,60 \\
\hline 1988 & 14,41 & 49,47 & 11,46 & 43,57 & 20,85 & - & 993,28 \\
\hline 1989 & 16,48 & 51,50 & 10,62 & 41,36 & 19,29 & - & $1.863,56$ \\
\hline 1990 & 14,20 & 48,78 & 11,45 & 41,92 & 19,95 & - & $1.585,18$ \\
\hline 1991 & - & - & - & - & - & - & 475,10 \\
\hline 1992 & 13,23 & 45,78 & 13,11 & 42,09 & 19,97 & 7,2 & $1.149,06$ \\
\hline 1993 & 15,09 & 48,64 & 12,31 & 42,98 & 20,27 & 6,8 & $2.489,11$ \\
\hline 1994 & - & - & - & - & - & - & 929,32 \\
\hline 1995 & 13,81 & 47,85 & 12,35 & 35,08 & 15,19 & - & 21,98 \\
\hline 1996 & 13,53 & 47,52 & 12,09 & 34,73 & 15,63 & 6,7 & 9,12 \\
\hline 1997 & 13,78 & 47,67 & 12,12 & 35,18 & 15,58 & 7,6 & 4,34 \\
\hline 1998 & 13,86 & 47,79 & 12,34 & 33,97 & 14,52 & 8,5 & 2,49 \\
\hline 1999 & 13,24 & 47,27 & 12,69 & 35,26 & 15,03 & 9,7 & 8,43 \\
\hline 2000 & - & - & - & - & - & - & 5,27 \\
\hline 2001 & 13,90 & 47,44 & 12,60 & 35,09 & 15,19 & 10,4 & 9,44 \\
\hline
\end{tabular}


MARCELLO BAQUERO; RODRIGO STUMPF GONZÁLEZ

\begin{tabular}{|c|c|c|c|c|c|c|c|}
\hline Ano & $\begin{array}{c}\text { Renda } \\
\text { domiciliar: } \\
\text { participação } \\
\text { do } 1 \% \text { mais } \\
\text { rico }\end{array}$ & $\begin{array}{c}\text { Renda } \\
\text { domiciliar: } \\
\text { participa- } \\
\text { ção dos } \\
10 \% \text { mais } \\
\text { ricos } \\
\end{array}$ & $\begin{array}{c}\text { Renda } \\
\text { domiciliar: } \\
\text { participa- } \\
\text { Ção dos } \\
50 \% \text { mais } \\
\text { pobres }\end{array}$ & $\begin{array}{c}\text { Pobreza: } \\
\text { taxa de } \\
\text { pobreza } \\
\text { (P0) }\end{array}$ & $\begin{array}{l}\text { Pobreza: } \\
\text { taxa de } \\
\text { extrema } \\
\text { pobreza } \\
\text { (P0) }\end{array}$ & $\begin{array}{c}\text { Taxa de } \\
\text { Desempre- } \\
\text { go }\end{array}$ & $\begin{array}{c}\text { Inflação } \\
\text { INPC }\end{array}$ \\
\hline 2002 & 13,42 & 47,03 & 12,97 & 34,38 & 13,98 & - & 14,74 \\
\hline 2003 & 13,08 & 46,20 & 13,22 & 35,75 & 15,18 & 10,1 & 10,38 \\
\hline 2004 & 12,98 & 45,33 & 13,83 & 33,71 & 13,22 & 9,7 & 6,13 \\
\hline 2005 & 12,99 & 45,33 & 14,05 & 30,83 & 11,50 & 10,2 & 5,05 \\
\hline 2006 & 12,77 & 44,75 & 14,45 & 26,75 & 9,45 & 9,2 & 2,81 \\
\hline 2007 & 12,51 & 43,85 & 14,72 & 25,36 & 8,96 & 8,9 & 5,16 \\
\hline 2008 & 12,12 & 43,06 & 15,30 & 22,60 & 7,56 & 7,8 & 6,48 \\
\hline 2009 & 12,10 & 42,74 & 15,50 & 21,41 & 7,27 & 9,1 & 4,11 \\
\hline 2010 & - & - & - & - & - & - & 6,47 \\
\hline 2011 & 11,76 & 41,81 & 16,15 & 18,42 & 6,31 & 7,3 & 6,08 \\
\hline 2012 & 12,58 & 41,90 & 16,38 & 15,93 & 5,29 & 6,7 & 6,20 \\
\hline 2013 & 11,74 & 41,55 & 16,42 & 15,09 & 5,50 & 7,1 & 5,56 \\
\hline 2014 & 11,35 & 40,89 & 17,00 & 13,29 & 4,20 & 7,5 & 6,23 \\
\hline
\end{tabular}

Fonte: Ipea, Ipeadata, 2016.

\section{Resumo}

Cultura política, mudanças econômicas e democracia inercial. Uma análise pós-eleições de 2014

Este artigo busca avaliar a presença de uma democracia inercial no Brasil, em que as assimetrias entre economia e política produzem uma cultura política passiva e anômica. Tal situação possibilita que as políticas sociais e econômicas sigam um padrão que pouco se modifica. Se, num contexto de mudanças, as coisas precisam mudar para que fiquem iguais, então se pode esperar que, num contexto de (re)democratização com inércia, as instituições mudem, sem, no entanto, alterar, numa direção positiva, as normas, os valores e as crenças normativas da população em relação à democracia. Para analisar essa proposição serão utilizados dados demográficos e socioeconômicos, avaliados ante a evolução da confiança nas instituições, governantes e na democracia no período 2002-2014, a partir de dados do Eseb. A conclusão é de que o período de desempenho econômico favorável não permitiu a consolidação de uma cultura política democrática, com rápida deterioração do apoio às instituições e aos governantes a partir da crise econômica.

Palavras-chave: cultura política; democracia inercial; economia

\section{Abstract \\ Political culture, economic changes, and inertial democracy: a post-2014 elections analysis}

This work seeks to evaluate the presence of an inertial democracy in Brazil, where asymmetries between economics and politics create a passive and anomic political culture. Such a situation allows for social and economic policies to follow a pattern that faces limited change. If, in a context of 
changes, things need to change in order to remain the same, then in a scenario of inertial (re-) democratization, institutions can be expected to change without, however, altering, in a positive direction, the population's norms, values, and normative beliefs about democracy. In order to assess this proposition, demographic and socio-economic data will be analyzed along with the evolution of trust in institutions, politicians, and democracy for the period of 2002-2014 using data from the Brazilian Electoral Survey (Eseb). The conclusion is that the period of favorable economic performance did not allow for the consolidation of a democratic political culture, with a rapid deterioration of support for institutions and leaders following the economic crisis.

Keywords: political culture; inertial democracy; economy

\section{Resumen}

Cultura política, cambios económicos y democracia inercial. Un análisis post-elecciones del 2014

Este trabajo tiene por objetivo evaluar la presencia de una democracia inercial en Brasil, donde las asimetrías entre economía y política crean una cultura política pasiva y anómica. Tal situación hace posible que las políticas sociales y económicas mantengan un patrón que poco cambia. En un contexto de cambios, son necesarios para que las cosas queden como están, se puede esperar que, en un contexto de (re)democratización con inercia, las instituciones cambien, sin, entretanto, alterar positivamente las normas, valores y creencias normativas del pueblo en relación con la democracia. Para analizar esta proposición, son utilizados datos demográficos y socioeconómicos, evaluados en su relación con la evolución de la confianza en las instituciones, gobernantes y en la democracia en el periodo 2002-2014, basado en datos del ESEB. La conclusión es que el periodo de desarrollo económico favorable no ha permitido la consolidación de una cultura política democrática, con el rápido deterioro del apoyo a las instituciones y gobernantes cuando llegó la crisis económica.

Palabras clave: cultura política; democracia inercial; economía

\section{Résumé}

Culture politique, transformations économiques et démocratie inertielle. Une analyse après les élections de 2014

Cet article cherche à évaluer la présence d'une démocratie inertielle au Brésil, où les asymétries entre l'économie et la politique développent une culture politique anomique et passive. Cet état des choses permet que les politiques sociales et économiques ne changent pas. Si, dans un contexte de changements, il faut que les choses changent pour que rien ne change, alors on peut $s$ 'attendre à ce que, dans un contexte de (re)démocratisation avec inertie, les institutions changent, mais sans modifier positivement les normes, les valeurs et les croyances du peuple vers la démocratie. Pour analyser cette proposition on utilisera des données démographiques et socio-économiques, évaluées dans le contexte de l'évolution de la confiance envers les institutions, les dirigeants et la démocratie pendant la période 2002-2014, à partir de données de I'Eseb. En conclusion, les résultats économiques favorables n'ont pas suffi pour développer une culture politique démocratique. Avec la crise économique, on a assisté à une rapide détérioration du soutien aux institutions et aux dirigeants.

Mots-clés: culture politique; démocratie inertielle; économie 